\title{
ESPAÇOS PÚBLICOS E PRÁTICAS \\ PARTICIPATIVAS NA GESTÃO DO MEIO AMBIENTE NO BRASIL
}

\author{
Pedro Roberto Jacobi*
}

Resumo: O objetivo deste texto é de aprofundar a reflexão em torno das dimensões da participação e das possibilidades de ampliação da cidadania na gestão do meio ambiente, com ênfase na gestão compartilhada de recursos hídricos. A análise focaliza, de um lado, o fortalecimento do espaço público e a abertura da gestão pública à participação da sociedade civil na elaboração de suas políticas públicas; e, de outro lado, a sempre complexa e contraditória institucionalização de práticas participativas inovadoras que marcam rupturas com a dinâmica predominante. Os temas aqui desenvolvidos estão organizados de forma a introduzir o leitor no universo de questões que, apesar da sua multiplicidade, se centram na associação entre cidadania, democracia participativa, governabilidade e sustentabilidade.

Palavras-chave: meio ambiente, gestão participativa, cidadania, sustentabilidade, políticas públicas ambientais.

\section{Introdução}

O objetivo deste texto é de aprofundar a reflexão em torno das dimensões da participação e das possibilidades de ampliação da cidadania na gestão do meio ambiente.

O desafio que nos colocamos é de analisar, de um lado, os impactos de práticas participativas que apontam, a partir da

* Professor Associado da Faculdade de Educação e do Programa de Pós-Graduação em Ciência Ambiental da Universidade de São Paulo.

Artigo recebido em 29 ago. 2003; aprovado em 1 out. 2003. 
manifestação do coletivo para uma nova qualidade de cidadania, que institui o cidadão como criador de direitos para abrir novos espaços de participação sociopolítica, e, de outro, os aspectos que configuram as barreiras que precisam ser superadas para multiplicar iniciativas de gestão que articulam eficazmente a complexidade com a democracia.

Existe uma crescente necessidade de entender as ambigüidades dos processos sociais e os arranjos possíveis, mas, principalmente, os limites nas experiências que inovam na gestão ambiental.

A análise focaliza o fortalecimento do espaço público e a abertura da gestão pública à participação da sociedade civil na elaboração de suas políticas públicas; e, também, aborda a sempre complexa e contraditória institucionalização de práticas participativas inovadoras que marcam rupturas com a dinâmica predominante.

Os temas aqui desenvolvidos estão organizados de forma a introduzir o leitor no universo de questões que, apesar da sua multiplicidade, centram-se na associação entre cidadania, democracia participativa, governabilidade e sustentabilidade.

\section{Participação e espaço público}

Na América Latina, a luta pela conquista de espaços para aumentar a participação social é, sem dúvida, um dos aspectos mais desafiadores para análise sobre os alcances da democracia. As experiências de deliberação participativa, desde o início dos anos 1980, no Brasil, estão associadas à capacidade que os movimentos sociais tiveram de explicitar demandas relacionadas principalmente com a distribuição de bens públicos e também, em menor escala, na formulação de políticas públicas. Parafraseando Eder Saber, "quando novos personagens entraram em cena", definiu-se um ponto de inflexão, no qual se amplia a participação popular na esfera pública e a conquista de direitos de cidadania.

Os novos arranjos participativos são reforçados a partir da Constituição de 1988, destacando-se o desenvolvimento de práticas 
que abrem espaço para a democracia participativa (Santos \& Avritzer, 2002; Dagnino, 2002). A revitalização da sociedade civil, desde meados da década de 1980, reflete-se no aumento do associativismo e na presença dos movimentos sociais organizados que se explicitam na construção de espaços públicos que pressionam pela ampliação e democratização da gestão estatal (Avritzer, 2002, Costa, 2002). Na década dos 90, a participação nas suas diversas dimensões é amparada e institucionalizada dentro dos marcos das democracias representativas. A participação popular transforma-se no referencial de ampliação de possibilidades de acesso dos setores populares dentro de uma perspectiva de desenvolvimento da sociedade civil $^{1}$ e de fortalecimento dos mecanismos democráticos, mas também para garantir a execução eficiente de programas de compensação social no contexto das políticas de ajuste estrutural e de liberalização da economia e de privatização do patrimônio do Estado.

A participação minimalista (Tanaka, 1995) aponta para o fato de que existe um déficit de participação e de constituição de atores relevantes, o que pode redundar em crescente fator de crise de governabilidade $^{2}$ e de legitimidade. A insatisfação pela deterioração ou a falta de melhoria nos níveis de qualidade de vida, sem canais efetivos onde estes possam ser explicitados, pode conduzir à erosão da titulariedade dos atores relevantes expressa em fenômenos como a volatilidade eleitoral e o desvirtuamento de propostas de gestão pautadas no aprofundamento das práticas democráticas. Poucas são, de fato, as experiências de gestão municipal que assumem uma radicalidade democrática na gestão da coisa pública, assim como ampliam concretamente o potencial participativo. A análise dos processos existentes está permeada pelos condicionantes da cultura política, tanto do Brasil como do resto dos países da América Latina, marcados por tradições estatistas, centralizadoras, patrimonialistas e, portanto, por padrões de relação clientelistas, meritocráticos e de interesses criados entre Sociedade e Estado. Entretanto, estes condicionantes não têm sido necessariamente um fator impeditivo para a emergência de uma diversidade de formas de participação dos setores populares, onde embora freqüentemente muitas se situem no escopo das práticas no contexto das tradições anteriormente descritas, outras as contradizem abertamente. 
A possibilidade de alterar a institucionalidade pública está associada às demandas que se estruturam na sociedade, e a esfera pública representa a construção da viabilidade ao exercício da influência da sociedade nas decisões públicas assim como coloca uma demanda de publicização no Estado. O que está em jogo é a necessidade de atualização dos princípios ético-políticos da democracia, onde o fortalecimento do tecido associativo potencializa o fortalecimento da democracia no resto das esferas da vida social. Segundo Putnam (1994), as práticas sociais que constroem cidadania representam a possibilidade de constituir-se num espaço privilegiado para cultivar a responsabilidade pessoal, a obrigação mútua e a cooperação voluntária. As práticas sociais que lhe são inerentes relacionam-se com a solidariedade e no encontro entre direitos e deveres. A ampliação da esfera pública tem colocado uma demanda à sociedade em termos de obter uma maior influência sobre o Estado, tanto como sua limitação, assumindo que a autonomia social supõe transcender as assimetrias na representação social, assim como modificar as relações sociais em favor de uma maior auto-organização social.

O fortalecimento da sociedade civil coloca em xeque as críticas em torno da distinção Estado/sociedade civil. ${ }^{3}$ A constituição de esferas públicas alternativas simultaneamente com a ampliação do espectro de problemas tratados publicamente estão associadas à emergência de novos atores coletivos, como é o caso do movimento ambientalista e ecologista. Segundo Bobbio (1987) a contraposição entre duas dinâmicas - "estatalização da sociedade" e "socialização do Estado - se dá "através do desenvolvimento de diversas formas de participação dentro das opções políticas, do crescimento das formas de organização de massa que exercem direta ou indiretamente algum poder político, onde a expressão "Estado social" pode ser entendida não só no sentido de Estado que permeou a sociedade, mas também no sentido de Estado permeado pela sociedade". Os dois processos representam, segundo o autor, "as duas figuras do cidadão participante e do cidadão protegido que estão em conflito entre si às vezes na mesma pessoa. Assim, "sociedade e Estado atuam como dois momentos necessários, separados mas contíguos, distintos mas 
interdependentes, do sistema social em sua complexidade e em sua articulação interna" (Bobbio, 1987).

Avritzer (1993) desenvolve sua análise em torno da abordagem habermasiana centrada no tema da esfera pública como caixa de ressonância dos problemas a serem organizados pelo sistema político. Para Habermas, segundo Avritzer "as sociedades modernas se estruturam através de dois princípios societários distintos: a lógica estratégica do sistema que organizaria o mercado e o Estado e a lógica da racionalidade comunicativa que leva à organização da solidariedade e da identidade no interior do mundo da vida. A disputa do espaço social nos pontos de encontro entre sistema e mundo da vida constituiria, segundo Habermas, a disputa política fundamental das sociedades contemporâneas".

Para Habermas, as sociedades modernas têm uma imagem multifacetada, onde a relação entre si de dois subsistemas diferenciados (Estado e mercado) que operam a partir de lógicas diferentes, e a relação entre cada um dos subsistemas ${ }^{4}$ e o mundo da vida $^{5}$ constituem o ponto focal de indissociáveis tensões (Arato \& Cohen, 1994).

A esfera pública é apontada por Habermas como ponto de encontro e local de disputa entre os princípios divergentes de organização da sociabilidade e os movimentos sociais se constituiriam nos atores que reagem à reificação e burocratização dos domínios de ação estruturados comunicativamente, defendendo a restauração das formas de solidariedade postas em risco pela racionalização sistêmica (Avritzer, 1993).

Para Arato \& Cohen (1994), “o entendimento das dimensões relevantes do mundo da vida, enquanto sociedade civil, é necessário para que seja alcançada a dupla tarefa da democracia radical autolimitada, a aquisição pelo público de influência sobre o Estado e a economia; a institucionalização dos ganhos dos movimentos sociais dentro do mundo da vida". Segundo estes autores, a questão política consiste em como introduzir espaços públicos no Estado e nas instituições econômicas, sem abolir os mecanismos reguladores da ação estratégica e estabelecendo uma continuidade com uma rede de 
comunicação social composta de movimentos sociais, associações e esferas públicas". Arato \& Cohen (1994) defendem, portanto, uma estratégia política dual, simultaneamente institucional e extrainstitucional. A possibilidade de alterar a institucionalidade pública está associada às demandas que se estruturam na sociedade, e a esfera pública representa a construção da viabilidade ao exercício da influência da sociedade nas decisões públicas assim como coloca uma demanda de publicização no Estado. O que está em jogo é a necessidade de atualização dos princípios ético-políticos da democracia, onde o fortalecimento do tecido associativo potencializa o fortalecimento da democracia no resto das esferas da vida social.

\section{A construção de espaços participativos no Brasil}

A redefinição das relações entre Estado e sociedade civil, ${ }^{6}$ no Brasil, no final dos anos 70, implica a constituição, com muitos percalços, de uma esfera societária autônoma. A cidadania regulada ${ }^{7}$ "constitui seletivamente os atores beneficiados pelo processo de modernização econômica, atores que, de acordo com os planejadores estatais, seriam capazes de trocar a cidadania social e civil pelo papel de membros de uma sociedade de consumo despolitizada" (Avritzer, 1994).

$\mathrm{O}$ advento da sociedade civil brasileira está indissoluvelmente vinculado não apenas à emergência de movimentos sociais, mas, conforme Avritzer (1994), ao "processo pelo qual atores sociais modernos e democráticos surgiram, adquiriram uma nova identidade democrática e passaram a pressionar o Estado e o sistema político a se adaptarem a uma nova concepção acerca da moderna institucionalidade democrática".

Os atores sociais que emergem na sociedade civil após 1970, à revelia do Estado, criaram novos espaços e formas de participação e relacionamento com o poder público. Estes espaços foram construídos, tanto pelos movimentos populares como pelas diversas instituições da sociedade civil que articulam demandas e alianças de resistência popular e lutas pela conquista de direitos civis e sociais. Muitos 
movimentos apontam, a partir da reposição do coletivo, para uma qualidade diferenciada de participação na gestão da coisa pública, onde a representação não resume todo o esforço de organização. Os movimentos tornam manifesta uma identidade que se concretiza a partir da construção coletiva de uma noção de direitos que, relacionada diretamente com a ampliação do espaço de cidadania, dá lugar ao reconhecimento público das carências.

O fato diferenciador destas transformações é, segundo Melucci (1994), o fortalecimento de novas instituições, as mudanças no relacionamento do quadro de pessoal com os usuários, a nova mentalidade sobre a gestão da coisa pública enquanto aspectos constitutivos de uma nova cultura política.

O processo de construção da cidadania é perpassado por paradoxos, na medida em que se explicitam três dinâmicas concomitantes: o reconhecimento e a construção das identidades dos distintos sujeitos sociais envolvidos, o contexto da inclusão das necessidades expressas pelos distintos sujeitos sociais e a definição de novas agendas de gestão, notadamente no que se refere à extensão dos bens a amplos setores da população. Esta noção de cidadania está estruturada a partir de uma definição legal dos direitos e deveres que a constituem. ${ }^{8}$

No Brasil, a reflexão em torno da cidadania ${ }^{9}$ centra-se em torno dos obstáculos à sua extensão, decorrentes da cultura política tradicional, e nas perspectivas da sua transformação.

Esta noção de cidadania ativa, que se distingue outorgada pelo Estado com a idéia moral do favor e da tutela (daquela cidadania passiva), está fortalecida pela Constituição de 1988, implicando o reconhecimento da complementariedade entre a representação política tradicional e a participação popular diretamente exercida (Benevides, 1994). A nova dimensão da cidadania inclui, de um lado, a constituição de cidadãos enquanto sujeitos sociais ativos, e, de outro lado, para a sociedade como um todo, um aprendizado de convivência com esses cidadãos emergentes que recusam permanecer nos lugares que lhes foram definidos social e culturalmente (Dagnino, 1994). 
No contexto da transição pós-democrática no Brasil, e por força das pressões de uma sociedade civil mais ativa e mais organizada, foram sendo criados novos espaços públicos de interação, mas principalmente de negociação. Nesse contexto, a participação social emerge principalmente como referencial de rupturas e tensões e as práticas participativas associadas a uma mudança qualitativa da gestão assumem visibilidade pública e repercutem na sociedade.

As transformações político-institucionais e a ampliação de canais de representatividade dos setores organizados para atuarem junto aos órgãos públicos, enquanto conquista dos movimentos organizados da sociedade civil, mostram a potencialidade de constituição de sujeitos sociais identificados por objetivos comuns para transformar a gestão da coisa pública, configurando a construção de uma nova institucionalidade.

O surgimento de políticas públicas pautadas pelo componente participativo, está relacionado com as mudanças na matriz sociopolítica através de um maior questionamento sobre o papel do Estado como principal agente indutor das políticas sociais. ${ }^{10}$ A noção de participação é pensada principalmente pela ótica dos grupos interessados e não apenas da perspectiva dos interesses globais definidos pelo Estado. O principal desafio que se coloca é de construir uma ordem societária baseada na articulação da democracia política com a participação social, representada por uma maior permeabilidade da gestão às demandas dos diversos sujeitos sociais e políticos. Essa perspectiva abre a possibilidade de buscar a articulação entre a implantação de práticas descentralizadoras e uma engenharia institucional que concilia participação com heterogeneidade, formas mais ativas de representatividade. Cabe observar os sempre permanentes e tensos vínculos entre representação e participação.

A participação social se enquadra no processo de redefinição entre o público e o privado, dentro da perspectiva de redistribuir o poder em favor dos sujeitos sociais que geralmente não tem acesso. Cunill Grau (1991) define dois campos interpretativos da participação. De um lado, aqueles que a associam com a democratização tendo como referência o fortalecimento do espaços de socialização, de 
descentralização do poder e de crescente autonomização das decisões, portanto, enfatizando a importância de um papel mais autônomo dos sujeitos sociais. O outro enfoque aborda a participação a partir da criação de espaços e formas de articulação do Estado com os sujeitos sociais, configurando um instrumento de socialização da política, reforçando o seu papel enquanto meio para realizar interesses e direitos sociais que demandam uma atuação pública (Cunill Grau, 1991).

Na última década, as formas de participação mais recorrentes estão centradas principalmente na criação de novos canais e mecanismos de relação entre a sociedade civil e a esfera pública (Dagnino, 2002). Esta nova esfera pública, que incide sobre o Estado, com ou sem suporte da representação política tradicional, é constituída por uma construção democrática e participativa que abre o Estado a um conjunto de organizações sociais admitindo a tensão política como método decisório, e diluindo, na medida do possível, as práticas autoritárias e patrimonialistas que também prevalecem na esfera urbana.

O principal exemplo está nos diferentes tipos de conselhos gestores de políticas públicas - saúde, educação, assistência social -, que apontam para a existência de um espaço público de composição plural e paritária entre Estado e sociedade civil de natureza deliberativa. Considerando-se que praticamente em todos os municípios do país existem conselhos de saúde e de educação, temse um importante contingente de cidadãos e cidadãs envolvidos em práticas participativas co-responsabilizadoras. Apesar dos conselhos gestores representarem arranjos institucionais inovadores, a grande indagação está relacionada com a capacidade de traduzir-se em práticas inovadoras e de uma efetiva democratização nos procedimentos de gestão dos assuntos públicos. Pesquisas mostram que os encontros entre Estado e Sociedade têm sido afetados negativamente por uma grande recusa do Estado em partilhar o poder de decisão (Tatagiba, 2002).

A efetiva participação da população nos processos decisórios, como é o caso do Orçamento Participativo em funcionamento em mais de 100 municípios no Brasil, vem se constituindo como um mecanismo ampliado de engajamento da sociedade na gestão das 
políticas públicas. Isto explicita um esforço crescente de institucionalização da possibilidade de atendimento das demandas em bases negociadas. Trata-se de processar demandas e pressões e de implementar mecanismos formais que contemplem, tanto os setores organizados e mobilizados estimulando sua adequação à institucionalidade respeitando a autonomia e a auto-organização, como o envolvimento dos setores desorganizados. Este processo de inovação social é definido por Avritzer (2002) como uma inovação entendida como uma prática societária de negociar abertamente o acesso a bens públicos que se torna um desenho participativo institucionalizado, por ele denominado de "públicos participativos". A radicalização da democracia que alarga os direitos de cidadania no plano político e social começa a substituir práticas das elites e o seu particularismo por formas ampliadas de discussão e tomada de decisão. Assim, neste processo de gestão através do ingresso da cidadania organizada na máquina do Estado, os participantes podem conhecer seu funcionamento e seus limites. Isto estimula a construção de uma relação de co-responsabilização e de disputa, visando produzir consensos cada vez mais qualificados.

As experiências dos Orçamentos Participativos estão diretamente vinculadas com a capacidade que as administrações locais têm de criar canais legítimos de participação, combinando elementos da democracia representativa e de democracia participativa. Tratase de experiências que se multiplicaram, representando em torno de 140 experiências entre 1997 e 2000 (Ribeiro \& Grazia, 2003) enquanto referência da adoção de um processo participativo, baseado no conceito de esfera pública não estatal que incide sobre o Estado, com ou sem o suporte da representação política tradicional. Nesse contexto, a participação adquire uma linguagem e uma prática de ruptura com o corporativismo territorialmente determinado, com ênfase numa lógica presidida por uma abordagem universal da cidade, criando para os setores populares, uma opção viável e altamente competitiva de participação política alternativa às práticas clientelistas. A distribuição das obras emerge de uma relação contratual previamente estabelecida através de um regulamento que determina as regras básicas de negociação interna de cada região da 
cidade e entre regiões, dificultando o clientelismo. Mas, apesar da sua repercussão positiva, também devem ser mostrados os seus limites, e estes residem, segundo os analistas, nas contradições associadas às dificuldades de ampliar a participação e a dependência em relação às autoridades municipais para estruturar a dinâmica de funcionamento (Navarro, 1999).

A efetiva participação da população nos processos decisórios, como é o caso Orçamento do Participativo, que tem se constituído como um mecanismo ampliado de engajamento da sociedade na gestão das políticas públicas, requer um esforço crescente de institucionalização da possibilidade de atendimento das demandas em bases negociadas. Trata-se de processar demandas e pressões e de implementar mecanismos formais que contemplem, tanto os setores organizados e mobilizados estimulando sua adequação à institucionalidade respeitando a autonomia e a auto-organização, como de envolvimento dos setores desorganizados. O Orçamento Participativo está legitimado e consta da agenda pública como mola propulsora do processo decisório da ação governamental. Isto está sendo construído dentro de uma lógica que não está apenas permeada pelo imediatismo e pelo utilitarismo, mas por uma radicalização da democracia que, alargando os direitos de cidadania no plano político e social, constrói efetivamente novas relações entre governantes e governados. Este processo de gestão através do ingresso da cidadania organizada na máquina do Estado, possibilita conhecer seu funcionamento e seus limites e estimula a construção de uma relação de co-responsabilização e de disputa, visando produzir consensos cada vez mais qualificados.

Embora o Orçamento Participativo apresente grandes variações nos seus resultados, trata-se de uma instituição inovadora que tem o potencial de afetar os cidadãos, a administração pública e a política de forma variada. Apresenta um potencial de promover educação pública, deliberação e resolução de disputas através do debate público. Assim, no Orçamento Participativo, "a gramática tem dois elementos: distribuição justa de bens públicos e negociação democrática do acesso a esses bens entre os próprios atores sociais (Santos \& Avritzer, 2002). 


\section{Participação da sociedade civil na gestão ambiental}

Na política ambiental é importante destacar também o surgimento e fortalecimento de numerosos conselhos, consultivos e deliberativos como parte componente, em várias áreas e em todos os níveis (federal, estadual e municipal) com a participação ativa de representantes de ONGs e movimentos sociais. As instâncias de gestão que agregam estes atores são os conselhos de meio ambiente, os comitês de bacias e as áreas de proteção ambiental (APAs). Entretanto, freqüentemente, são instâncias bastante formais, sem poder influenciar no processo decisório, e onde a representação assume muitas vezes caráter bastante contraditório.

Os conselhos de meio ambiente, órgãos integrantes do Sistema Nacional do Meio Ambiente (SISNAMA), instituído pela Lei de Política Nacional do Meio Ambiente (Lei no 6.938/81), são espaços públicos que definem parâmetros de gestão da coisa pública, que deliberam sobre normas, padrões e regulamentos ambientais. Estes conselhos são colegiados representativos dos diversos setores do governo (federal, estaduais, municipais) e da sociedade civil que lidam direta ou indiretamente com o meio ambiente. O CONAMA faz parte da estrutura básica do Ministério como órgão consultivo e deliberativo do Sistema, sendo composto de Plenário e Câmaras Técnicas, com representação de diferentes setores do governo e da sociedade civil. Suas atribuições são: estudar e propor diretrizes de políticas governamentais para o meio ambiente e para os recursos naturais; estabelecer normas e critérios para licenciamento de atividades poluidoras; determinar a realização de estudos sobre as alternativas e possíveis conseqüências ambientais de projetos públicos ou privados; decidir como última instância sobre multas ou penalidades; submeter propostas referentes à concessão de incentivos e benefícios fiscais e financeiros visando à melhoria da qualidade ambiental.

O Conselho Nacional do Meio Ambiente (CONAMA) aprovou, desde 1981 até 2002, mais de 280 resoluções que têm impacto na gestão ambiental (BID, 2002, p. 64). A criação do SISNAMA e do CONAMA incentivaram significativamente a participação da sociedade civil nas atividades de proteção ambiental e promoveram importantes mudanças no desenvolvimento da legislação ambiental. 
Representantes da sociedade civil participam praticamente de todas as decisões em todos os conselhos e comitês gestores do Ministério.

O sistema ambiental colegiado está implementado no Brasil, e isto representa uma efetiva possibilidade de internalizar a questão ambiental nas políticas estaduais e municipais, quando existentes. Nos conselhos estaduais e naqueles municípios que também os implantaram, os resultados têm sido muito desiguais, com significativas diferenças entre regiões, sendo que na maioria dos casos, existe ainda uma prevalência das decisões definidas pela presença muitas vezes majoritária da representação governamental, o que aumenta em muito o poder de manipulação dos consensos e dos resultados, e quanto mais ampla a representação dos diversos segmentos, maior a legitimidade das decisões.

Apesar de ter passado durante os últimos anos por duas grandes dificuldades, a falta de recursos financeiros e o refluxo pós-Rio 92, as ONGs ambientalistas têm exercido um papel relevante em muitos conselhos estaduais e municipais. A partir de 1992 algumas redes e coalizões se estruturam com o objetivo de enfrentar tanto em nível nacional como regional, conforme os objetivos e questões em pauta, temas críticos que demandam organização, articulação e mobilização. Entram em pauta de forma cada vez mais significativa a discussão do modelo de desenvolvimento, a necessidade do aprofundamento das análises sobre o quadro socioambiental existente, a identificação dos principais impactos ambientais e sociais e a articulação das entidades civis no plano local e internacional.

Outra forma de gestão colegiada e deliberativa são os Comitês de Bacias Hidrográficas, integrados por representantes do governo estadual, municipal e membros de entidades e organizações da sociedade civil. O seu início ocorre no Estado de São Paulo com a aprovação da Lei 7.663/91 que cria inicialmente dois comitês de bacias hidrográficas com composição tripartite (Estado, municípios e sociedade civil). A gestão de bacias hidrográficas assume crescente importância no Brasil, à medida que aumentam os efeitos da degradação ambiental sobre a disponibilidade de recursos hídricos. A Lei Federal $n^{\circ}$ 9.433, de 1997, estabelece os novos procedimentos a serem adotados na gestão da água, sobressaindo-se que o 
gerenciamento da água deverá ser realizado por bacia hidrográfica e que a água passa a ter valor econômico.

Ao longo da década de 90, a União e a maioria dos Estados aprovaram leis que reorganizaram o sistema de gestão de recursos hídricos. O novo sistema reconhece a água como bem econômico, preconiza uma gestão integrada e descentralizada dos usos múltiplos da água, e requer negociações entre órgãos de diferentes níveis de governo (federal, estadual e local), usuários e a sociedade civil organizada. O processo de negociação ocorre em nível de bacia hidrográfica, através de organizações de bacias. Esses colegiados deliberam sobre as atividades e políticas públicas que possam afetar a quantidade e a qualidade das águas em suas circunscrições. Têm o poder de cobrar pelo uso da água através de seus braços executivos, as agências de bacia, e de decidir sobre a alocação dos recursos arrecadados. A efetivação do processo de gestão em bacias hidrográficas, de acordo com a nova lei, ainda é embrionária, e a prioridade dos organismos de bacia é na criação dos instrumentos necessários para a gestão.

O sistema é inovador, tanto no Brasil como internacionalmente. Rompe com práticas profundamente arraigadas de planejamento tecnocrático e autoritário, devolvendo poder para as instituições descentralizadas de bacia. Os alcances das experiências têm sido desiguais, destacando a constituição de organismos colegiados de tomada de decisão. Estima-se atualmente em mais de uma centena o número de comitês de bacias instalados no país, notadamente nas regiões Sudeste e Sul, na sua maioria estruturados no âmbito estadual, entretanto mostram avanços quanto ao engajamento no processo decisório. Até 2003, mais de uma década após a aprovação da primeira lei das águas no país, nenhum sistema foi operacionalizado por completo.

A lógica do colegiado permite que os atores envolvidos atuem, em princípio, tendo um referencial sobre seu rol, responsabilidades e atribuições no intuito de neutralizar práticas predatórias orientadas pelo interesse econômico ou político. A dinâmica do colegiado facilita uma interação mais transparente e permeável no relacionamento entre os diferentes atores envolvidos - governamentais, empresariais e 
usuários. Isto limita as chances de abuso do poder, entretanto não necessariamente da manipulação de interesses pelo executivo. Isto dependerá, principalmente da capacidade de organização dos segmentos da sociedade civil. Outros riscos são sensivelmente atenuados, como, por exemplo, a captura da instituição por interesses específicos, que contrastam com a sua finalidade coletiva.

Entretanto, a composição dos Comitês tem sido objeto de diversos questionamentos, sobretudo pela imprecisão do conceito "participação". Na última década, o termo "abordagem participativa" passou a fazer parte dos discursos governamentais, de ONGs e de diferentes agências internacionais de desenvolvimento. Mas o conceito de participação pode implicar diversos significados, nem sempre explicitados. Os questionamentos em relação a um uso indiferenciado do conceito de abordagem participativa têm aumentado, sobretudo na bibliografia sobre desenvolvimento sustentável. A interveniência de fatores não apenas técnicos, mas também de caráter político, econômico e cultural, tornam o processo muito mais complexo, e o estilo de gestão que tende a prevalecer obedece a uma lógica sociotécnica. Entretanto, não se deve pressupor que a boa vontade dos peritos/técnicos pode levar a diluir magicamente as relações de poder que estabelecem com setores leigos. Estas relações de poder não desaparecem, mas passam a ser trabalhadas e negociadas conjuntamente entre leigos e peritos. Assim, a gestão colegiada tende a definir uma dinâmica que permite que os atores integrem e ajustem suas práticas tendo como base uma lógica de negociação sociotécnica que substitui uma concepção tecnocrática visando ajustar interesses e propostas nem sempre convergentes e articulados para um objetivo comum.

O maior problema com o qual se têm defrontado muitos comitês, é o fato de os diversos atores envolvidos na dinâmica territorial terem visões do processo e dos objetivos que, pelo fato de serem divergentes, dificultam a busca de soluções que parecem mais eqüitativas. $\mathrm{O}$ espírito presente numa negociação em bases sociotécnicas é marcado pela negociação entre diferentes, e parte da premissa das assimetrias na situação dos atores, tanto em termos econômicos, sociais e políticos. A grande questão que se coloca é quanto à capacidade de negociação e de estabelecer pactos. Dada a complexidade do processo e as 
dificuldades de se consolidar um parâmetro de cidadania ambiental, os limites estão dados pela prevalência de lógicas de gestão que ainda centram, na maioria dos casos, uma forte prevalência do componente técnico como referencial de controle do processo.

O princípio da gestão descentralizada, integrada, colegiada e participativa, ainda está no seu início, e os entraves são significativos e diferenciados. A possibilidade efetiva de mudança do paradigma e os desafios que se apresentam para a implementação de práticas participativas estão intimamente relacionados com o papel dos gestores e a lógica dos "sistemas peritos" (Giddens, 1992). Existe uma certa ambigüidade na legislação, que por um lado abre os espaços para a participação da sociedade civil, mas supõe um certo acesso às informações técnicas. Observa-se que, apesar dos avanços, a Lei $\mathrm{n}^{\circ}$ 9.433/97 coloca em primeiro plano a importância do corpo técnicocientífico e do conhecimento por ele produzido nas relações de força no interior dos espaços decisórios da bacia, o que limita o envolvimento da comunidade nas atividades dos Comitês. Assim, mantém o poder decisório entre os que detêm o conhecimento técnicocientífico. As mudanças em curso representam uma possibilidade efetiva de transformação da lógica de gestão da administração pública nos Estados e municípios, abrindo um espaço de interlocução muito mais complexo e ampliando o grau de responsabilidade de segmentos que sempre tiveram participação assimétrica na gestão da coisa pública.

O que cabe registrar, é que a existência dos Comitês de Bacias estabelece uma mudança, também, quanto ao relacionamento entre Estado e Sociedade Civil, na medida em que as regras do jogo voltamse mais para o uso da água e passam a articular um número maior de atores no processo decisório.

No IV Encontro de Comitês de Bacias, em 2002, os participantes confirmaram que desde a implantação do modelo dos Comitês priorizou-se a auto-afirmação de entidades representativas de corporações profissionais que ajudaram a implementar o próprio modelo e que podem continuar mantendo-se como representantes da sociedade civil, e reproduzindo o monopólio dos peritos na gestão 
dos recursos hídricos. Isto seria devido à falta de informações disponíveis ou ao predomínio da informação técnica sobre a importância do Comitê, o que geraria pouco interesse da comunidade para participar, obrigando algumas vezes ao preenchimento de vagas não só por peritos mas também por outros setores pouco representativos.

\section{Avanços na gestão compartilhada do meio ambiente e principais desafios}

Os complexos e desiguais avanços revelam que estas engenharias institucionais, baseadas na criação de condições efetivas para multiplicar experiências de gestão participativa que reforçam o significado da publicização das formas de decisão e de consolidação de espaços públicos democráticos, ocorrem pela superação das assimetrias de informação e pela afirmação de uma nova cultura de direitos. Estas experiências que denominamos inovadoras, fortalecem a capacidade de crítica e de interveniência dos setores de baixa renda através de um processo pedagógico e informativo de base relacional, assim como a capacidade de multiplicação e aproveitamento do potencial dos cidadãos no processo decisório.

O principal resultado da implementação dos conselhos de meio ambiente, que constituem mais de 500 no nível estadual e milhares no nível municipal, é a sinergia que se cria, apesar das tensões e contradições entre representantes de governo e diferentes segmentos da sociedade criadas tanto por excesso de burocracia e a complexidade de muitos procedimentos que desestimulam a participação dos cidadãos. Além disso é sempre bom reforçar o fato de que as desigualdades econômicas e a pressão política valorizam excessivamente o papel de alguns atores em detrimento de outros. Assim, nos conselhos freqüientemente ocorre uma inibição de alguns agentes quando outros se diferenciam pelo seu poder econômico e/ou político em processos de tomada de decisão e consulta (Furriela, 2002).

Em muitos casos, os CONSEMAs e CONDEMAs se transformam em órgãos majoritariamente controlados pelo Executivo. Isto coloca em questão a governança ambiental, na medida em que 
existe pouca cooperação em nome de interesses compartilhados, reduzindo a possibilidade de um efetivo confronto entre interesses conflitantes. Um dos grandes fatores limitantes é a irregularidade da participação, com a troca freqüente de atores no desenrolar das análises.

A contribuição dos espaços deliberativos é fundamental para o fortalecimento de uma gestão democrática, integrada e compartilhada. A ampliação destes espaços de participação cidadã favorece qualitativamente a capacidade de representação dos interesses e a qualidade e equiidade da resposta pública às demandas sociais. Essas experiências demonstram a importância do exercício da participação civil nos conselhos ambientais, assim como os de educação, saúde, assistência social, habitação, enquanto espaços de questionamento não apenas da forma do processo decisório do Estado, mas também das relações entre Estado e Sociedade Civil no campo das políticas públicas.

O grande desafio é que esses espaços sejam efetivamente públicos, tanto no seu formato quanto nos resultados. A dimensão do conflito lhes é inerente, como à própria democracia. Assim, os espaços de formulação de políticas onde a sociedade civil participa, marcados pelas contradições e tensões, representam um avanço na medida em que publicizam o conflito e oferecem procedimentos - discussão, negociação e voto - e espaço para que seja tratado de forma legítima. A criação de condições para uma nova proposta de sociabilidade deve ser crescentemente apoiada em processos educativos orientados para a "deliberação pública". Esta se concretizará principalmente pela presença crescente de uma pluralidade de atores que, através da ativação do seu potencial de participação terão cada vez mais condições de intervir consistentemente e sem tutela nos processos decisórios de interesse público, legitimando e consolidando propostas de gestão baseadas na garantia do acesso à informação, e na consolidação de canais abertos para a participação que, por sua vez, são pré-condições básicas para a institucionalização do controle social. Não basta assegurar legalmente à população o direito de participar da gestão ambiental, estabelecendo-se conselhos, audiências públicas, fóruns, procedimentos e práticas. $\mathrm{O}$ desinteresse e freqüente apatia 
da população quanto à participação é generalizada, resultado do pequeno desenvolvimento de sua cidadania e do descrédito nos políticos e nas instituições.

Essas considerações só poderão ser colocadas em prática a partir de um processo de aprendizagem que implica a reorganização das relações entre o setor privado, o governo e a sociedade civil. Isto implica mudanças no sistema de prestação de contas à sociedade pelos gestores públicos e privados, mudanças culturais e de comportamento. Dependemos de uma mudança de paradigma para assegurar uma cidadania efetiva, uma maior participação e a promoção do desenvolvimento sustentável.

A participação assume um papel cada vez mais relevante na denúncia das contradições entre os interesses privados e os interesses públicos na construção de uma cidadania ambiental que supere a crise de valores e identidade e proponha uma outra, com base em valores de sustentabilidade. Isto potencializa a ampliação da consciência ambiental e sua tradução em ações efetivas de uma população organizada e informada de maneira correta, que está preparada para conhecer, entender, reclamar seus direitos e também para exercer sua responsabilidade. Pessoas cidadãs críticas e conscientes compreendem, se interessam, reclamam e exigem seus direitos ambientais junto ao setor social correspondente e, por sua parte, estão dispostas a exercer sua responsabilidade ambiental. Uma sociedade civil se organiza e participa da direção de sua própria vida, e isto permite que as pessoas adquiram um poder político e a capacidade de produzir mudanças. Isto reforça a necessidade de identificar os papéis e as responsabilidades dos diversos atores diante de temas ambientais e também a necessidade de construir consensos em torno deles. À medida que o Estado terá, cada vez mais, que dar respostas em relação ao desenvolvimento sustentável, os cidadãos devem ser parte integrante de uma visão comum de longo prazo.

Os mecanismos de participação aumentaram nos últimos 10 anos, mas ainda não fazem diferença. Apesar de terem se democratizado, os mecanismos são mal aproveitados pela população, como no caso das audiências públicas. Em geral, a população aproveita a disponibilidade dos mecanismos de forma contraditória, a partir 
de uma visão imediatista, mas o aproveitamento é muito limitado, até porque a grande maioria da população não tem conhecimento sobre os mecanismos existentes, e como poderiam ser aproveitados para pressionar o governo.

Existem mais possibilidades de participação, mas com a falta de credibilidade e a falta de continuidade administrativa que ainda prevalece, a população perdeu a noção da consistência das políticas e do seu alcance.

É necessário incrementar os meios e o acesso à informação, assim como o papel indutivo que o poder público deve ter na oferta de conteúdos informacionais e educativos. Emergem assim, indagações quanto aos condicionantes de processos que ampliem as possibilidades de alteração do atual quadro de degradação socioambiental.

Assim, é preciso pensar a questão da sustentabilidade para reforçar políticas socioambientais que se articulem com as outras esferas governamentais e possibilitem a transversalidade. A implementação de ações implica não somente uma articulação sociopolítica, mas também um acordo quanto aos procedimentos de disseminação pública - tanto através de campanhas públicas de informação quanto de mecanismos orientados para a constituição de um esforço comunitário para estimular e consolidar um eficiente e consistente processo de participação. Para tanto, torna-se essencial o estímulo aos diversos atores sociais abertamente motivados, visando multiplicar informações, decodificá-las e superar os níveis de desinformação e desinteresse das pessoas, através de um crescente processo de implementação de políticas públicas pautadas por uma lógica de co-responsabilização.

Melhor acesso à informação e o incremento de participação social têm promovido mudanças de atitude que favorecem o desenvolvimento de uma consciência ambiental coletiva e de um envolvimento crescente da sociedade civil nos espaços deliberativos onde pensamentos plurais se apresentem e os conflitos ganhem visibilidade. 
O reforço destas práticas, no debate e na deliberação no interior dos espaços de formulação de políticas ambientais, contribui para a construção de uma sociedade mais comprometida com a constituição do interesse público e para um maior engajamento de atores relevantes na definição de políticas ambientais centradas no interesse público.

\section{Notas}

1 Para Hegel "a sociedade civil representa o primeiro momento de formação do Estado, o Estado jurídico-administrativo, cuja tarefa é regular relações externas, enquanto o Estado propriamente dito representa o momento ético-político, cuja tarefa é realizar a adesão íntima do cidadão à totalidade de que faz parte, tanto que poderia ser chamado de Estado interno ou interior"(cf. Bobbio, 1987, p. 42).

2 Adotamos o conceito sistematizado por Mello (1995, p. 30) que qualifica o modo de uso da autoridade política - formato institucional dos processos decisórios, definição do mix público/privado nas políticas, questões de participação e descentralização, mecanismos de financiamento das políticas e do escopo global dos programas (focalizados versus universalistas).

3 Para uma reflexão aprofundada em torno dos diversos enfoques, ver Santos (1996, p. 117-120).

4 Trata-se do econômico, que se organiza em torno da lógica estratégica do intercâmbio que permite a comunicação através do código positivo da recompensa, e do administrativo, que se organiza em torno da lógica estratégica do poder que permite a comunicação através do código negativo da sanção (Avritzer, 1993, p. 215-216).

5 O conceito habermasiano de mundo da vida contém três componentes estruturais distintos: a cultura, a sociedade e a personalidade. Na medida em que estes atores se entendem mutuamente e concordam sobre a sua condição, eles partilham uma tradição cultural e por meio das regras e normas estabelecidas pelos atores se internalizam orientações valorativas, adquirem-se novas competências para o agir cotidiano, no movimento e fora dele, e desenvolvem-se identidades individuais e sociais. A reprodução de ambas as dimensões do mundo da vida envolve processos comunicativos de transmissão da cultura, de integração social e de socialização. A diferenciação estrutural do mundo da vida se dá por intermédio da 
emergência de instituições especializadas na reprodução de tradições, solidariedades e identidades (Arato \& Cohen, 1994, p. 153 ).

6 Para Habermas, a sociedade civil constitui uma dimensão do mundo da vida assegurada institucionalmente por um conjunto de direitos que a pressupõem, ao mesmo tempo que a diferenciam das esferas da economia e do Estado (Arato \& Cohen, 1994).

7 Para uma reflexão em torno da questão, cf. Santos, W. G. (Cidadania e Justiça, 1979).

8 Há dois eixos centrais do debate ideológico, teórico e político: a natureza dos sujeito e o conteúdo dos direitos. O primeiro refere-se à visão liberalindividualista e o segundo à existência de direitos universais e à relação entre direitos humanos, civis, políticos, econômico-sociais e coletivos. (Jelin, 1994, p. 43).

9 Para um aprofundamento da noção de cidadania, ver Maria V. Benevides (1991). A autora aponta o caminho da democracia semidireta como meio de recuperar a soberania popular: a associação da democracia representativa com mecanismos de democracia direta.

10 A estratégia proposta pela CEPAL, em documentos publicados nos anos 80, reconhece a necessidade de adequar o Estado aos desafios de uma nova estratégia de inclusão nos processos sociopolíticos dos cidadãos na qualidade de cidadãos plenamente participativos, (Cunill Grau, 1991).

\begin{abstract}
The scope of this article is centered in analysis on the dimensions of participation and the possibilities of enlargement of citizenship in the management of environment in Brazil, with emphasis on the partaged management of water sources. The analysis is centered on the strengthening of public space and the opening of public management to the participation of civil society in the fomulation and definition of public policies. It also approaches issues linked to the always complex and contradictory institutionalization of innovative participatory practices that establish ruptures with the prevailing dynamics. The themes developed in this article are organized as to introduce the reader within a set of issues that, notwithstanding their multiplicity, are centered on the association between citizenship, participatory democracy, governance and sustainability.
\end{abstract}

Key-words: environment, participative management, citizenship, sustainability, environmental public policies. 
Résumé: Cet article présente une analyse sur les dimensions de la participation et les conditions d'enlargement de la citoyenneté dans la gestion de l'environnement au Brésil. L'argumentation est centrée dans la gestion partagée de l'eau. Le texte débat l'expansion de l'espace public et l'ouverture de la gestion publique à la participation de la societé civile dans la formulation et définition des politiques publiques liées à l'environnement et les liaisons entre citoyenneté, democratie participative, gouvernance et developpement soutenable.

Mots-clés: environnement, gestion participative, citoyenneté, développement durable, politiques publiques envirommentales.

\section{Referências bibliográficas}

ARATO, A; COHEN, J. Sociedade civil e teoria social. In: AVRITZER, L. Sociedade civil e democratização. Belo Horizonte: Del Rey, 1994.

AVRITZER, L. Democracy and the public space in Latin America. New Jersey: Princeton University Press, 2002.

AVRITZER, L.; NAVARRO, Z. (Orgs.). A inovação democrática no Brasil. São Paulo: Cortez Editora, 2003.

BENEVIDES, M. V. Cidadania ativa. São Paulo: Ática, 1994.

BID. Diálogos e política social e ambiental: aprendendo com os Conselhos Ambientais Brasileiros. Brasília: BID, 2002.

BOBBIO, N. Estado, Governo, Sociedade. São Paulo: Paz e Terra, 1987.

BRESSER PEREIRA, L.C.; CUNILL GRAU, N. (Orgs.). O público nãoestatal na reforma do Estado. Rio de Janeiro: Editora da Fundação Getúlio Vargas, CLAD, 1999.

COSTA, S. As cores de Ercília. Belo Horizonte: Editora da UFMG, 2002.

CUNNILL GRAU, N. Participación ciudadana. Caracas: CLAD, 1991.

CUNILL GRAU, N. Repensando o público através da sociedade. Rio de Janeiro: Revan, ENAP, 1991.

. Os movimentos sociais e a emergência de uma nova noção de cidadania. In: DAGNINO, E. (Org.) Política e sociedade no Brasil. São Paulo: Brasiliense, 1994. p.103-118.

Sociedade civil, espaços públicos e a construção democrática no Brasil: limites e possibilidades. In: DAGNINO, E. (Org.) Sociedade 
civil e espaços públicos no Brasil. São Paulo: Paz e Terra, 1994. p. 279-301.

FURRIELA, R. Democracia, cidadania e proteção do meio ambiente. São Paulo: Annablume, 2002.

GIDDENS, A. Conseqüências da modernidade. São Paulo: UNESP Editora, 1992.

MELUCCI, A. Movimentos sociais, renovação cultural e o papel do conhecimento. Entrevista feita por Avritzer, L. e Lyra, T. Revista Novos Estudos CEBRAP, São Paulo, v. 40, p. 152-166, 1994.

NAVARRO, Z. Democracia e controle social de fundos públicos: o caso do "orçamento participativo" de Porto Alegre (Brasil). In: BRESSER PEREIRA, L.C.; CUNILL GRAU, N. (Orgs.). O público não-estatal na reforma do Estado. Rio de Janeiro: Editora da Fundação Getulio Vargas, CLAD, 1999. p. 293-334.

PUTNAM, R. Making democracy work. New Jersey: Princeton University Press, 1994.

RIBEIRO, A. C. Experiências de orçamento participativo no Brasil. Petrópolis: Vozes, 2003.

SADER, E. Quando novos personagens entraram em cena. São Paulo: Paz e Terra, 1989.

SANTOS, B. Pela mão de Alice. São Paulo: Cortez, 1996.

SANTOS, B.; AVRITZER, L. Para ampliar o cânone democrático. In: SANTOS, B. (org.) Democratizar a democracia. Rio de Janeiro: Civilização Brasileira, 2002. p. 39-82.

TANAKA, M. La participación politica de los sectores populares en América Latina. Revista Mexicana de Sociologia, Mexico, v. 3, p. 41-66, 1995.

TATAGIBA, L. Os conselhos gestores e a democratização das políticas públicas no Brasil. In: DAGNINO, E. (Org.) Sociedade civil e espaços públicos no Brasil. São Paulo: Paz e Terra, 2002. p. 47-103.

TELLES, V. Sociedade civil e a construção de espaços públicos. In: DAGNINO, E. (Org.). Anos 90: política e sociedade no Brasil. São Paulo: Brasiliense, 1994. p. 91-102. 